\title{
Application of Strategic Fuzzy Assessment for Environmental Planning; Case of Bird Watch Zoning in Wetlands
}

\author{
Mostafa Biglarfadafan1, Afshin Danehkar², Sharareh Pourebrahim³ ${ }^{3}$ Afshin Alizadeh Shabani', \\ Mazaher Moeinaddini ${ }^{5}$
}

\footnotetext{
${ }^{1}$ Natural Resources Environment Engineer, Department of Agriculture and Natural Resources, University of Tehran, Tehran, Iran ${ }^{2}$ Coastal Environment, Department of Environment, Tarbiat Modares University, Tehran, Iran

${ }^{3}$ Planning and Environmental Management, Department of Environment, Universiti Putra Malaysia, Seri Kembangan, Malaysia

${ }^{4}$ Wildlife Ecology, Department of Environment, RMIT University, Melbourne, Australia

${ }^{5}$ Natural Resources Environment Engineer, Department of Environment, Tarbiat Modares University, Tehran, Iran

Email: mostafa.biglar@yahoo.com
}

How to cite this paper: Biglarfadafan, M., Danehkar, A., Pourebrahim, S., Shabani, A.A. and Moeinaddini, M. (2016) Application of Strategic Fuzzy Assessment for Environmental Planning; Case of Bird Watch Zoning in Wetlands. Open Journal of Geology, 6, 1380-1400.

http://dx.doi.org/10.4236/ojg.2016.611099

Received: September 5, 2016

Accepted: November 11, 2016

Published: November 15, 2016

Copyright $\odot 2016$ by authors and Scientific Research Publishing Inc. This work is licensed under the Creative Commons Attribution International License (CC BY 4.0).

http://creativecommons.org/licenses/by/4.0/ (c) (i) Open Access

\begin{abstract}
Strategic assessments are a landscape scale assessment and unlike project-by-project assessments which look at individual actions, they can consider a much broader set of issues; for example, a large urban growth area that will be developed over many years or a fire management policy across a broad landscape. Wetlands are important and effective ecosystems for biodiversity protection and improving environmental conditions. Bird watching as tourism and ecotourism activity is a complex process which it is compatible with conservation of wetlands and other aquatic zones. In this research, combination of SWOT analysis and FAHP method base on strategic fuzzy assessment are used for bird watch zoning in Bazangan Lake. By making internal and external matrix for SWOT factors, existing condition was in competitive strategies (ST) in the study area. Offered strategies in this condition were environment restoration to increase in environment resilience against hazards (natural and human), avoiding of land use and land cover changes and presence of ecotourism responsibly especially Bird watching. The sensitivity analysis results did not show any difference within the results of the present study and it was suitable and valid to use for similar situations. Base on the presented medium and short term strategies, it needed to have a short time training program to inform and empower local communities to wetlands partnership management by sharing them in the getting benefits in Bazangan Lake. By using the preferred frame in this study, decision makers can plan for each lake, dam and wetland and determine the best areas for tourist activities like bird watching. Conservation, protection and restoration of environment with its wildlife
\end{abstract}


are guaranteed by using fuzzy assessment to provide reasonable strategies.

\section{Keywords}

Bird Watching, SWOT, FAHP, Strategic Fuzzy Assessment, The Sensitivity Analysis

\section{Introduction}

Strategic assessments are landscape scale assessments and unlike project-by-project assessments which look at individual actions, they can consider a much broader set of actions, for example, a large urban growth area that will be developed over many years, or a fire management policy across a broad landscape. In the recent years, decisions are made in increasingly complex environments, as Multi-Criteria Decision-Making (MCDM) problems and stakeholders have dealt with many issues. The aim of MCDM is to give solutions and propose the best or a set of good alternative(s) for solving the problems with multiple criteria. The results will be affected by decision makers' priorities during giving ranks to the criteria and sub criteria [1] [2].

Wetlands are the most diverse ecosystems and have important functions that include important role in the water cycle, erosion control, water treatment, reuse of elements, the transition zone between land and water ecosystems, absorbing and converting of the chemical and biological ingredient, safe place for wildlife especially endangered species and suitable place for tourism such as wildlife tourism [3] [4]. The wildlife tourism process can be occurred according to tourists' motivations [5] [6] such as whale and dolphin tourism, bird watching, safari tours, butterfly watching holidays, polar bear viewing and general nature-orientated tours to observe reptiles, insects, and plants.

Assessment of a wetland ecosystem is to analyze the possible effects on the changing biodiversity of the particular wetland under environmental factors on a regional scale. The major threats to proper management of wetlands are excessive usage of technology and lack of knowledge among different stakeholder's viz. farmers, conservationists and recreationists.

Bird watching is an activity base on the nature-based tourism, which is correlated with the direct enjoyment of intact some deal phenomenon of nature. Cause of this treatment is getting to touch with nature, escape the stresses of daily life, and enjoy views of natural landscapes and wildlife [7]. Importance of Bird watching has grown in the recent decades as a new branch of ecological tourism. Not only it helps for economic development and environmental management to rural areas, but also it emerges as one of the most important ecologically and sustainable classes of wildlife tourism. Bird watching requires at the least equipment to start and a minimum level of physical ability to present and participate.

In recent years, different types of models have evolved for strategic planning and land evaluation. Among these models, SWOT (Strength, Weaknesses, Opportunities, 
Threats) is used more than others specially in field of the ecotourism strategic planning [8] [9], detecting land use change [10], regional assessment [11], and the planning and management of wetlands and coastal areas. By combination SWOT analysis and MCDA (e.g. AHP (Analytical Hierarchy Process), ANP (Analytical Network Process) and FAHP (Fuzzy Analytical Hierarchy Process)) can improve prioritizing of strategic alternatives [12]. This combination is used in various fields such as forestry [13] [14] [15] and tourism [16].

Turning attention to the applied aspect of Fuzzy AHP technique in the literature, it has been applied by many researchers for making decision in different fields. Some recent examples of Fuzzy AHP applications can be considered next [17]. [18] developed a modified Fuzzy AHP for the project risk assessment. [19] applied Fuzzy extended AHP methodology on shipping registry selection in the Turkish maritime industry. [20] considered a holistic approach using the FAHP to find priority sequence of alternatives and obtain the key success factors for the selection of appropriate sites of wind farms. [21] used a Fuzzy analytic hierarchy process for multiple criteria ABC inventory classification in a large power engineering company of Bangladesh. [22] proposed a Fuzzy AHP based approach to select the optimal alternative for construction of an underground dam in Iran's Kerman province. [23] applied a Fuzzy AHP approach for supplier selection in a gear motor company in Turkey. [24] used a Fuzzy AHP approach for choosing of measuring instrument for engineering college selection in India. Anvary [25] applied a Fuzzy Hierarchal Analysis Process (FAHP) for evaluation of the effects of Information Technology (IT) capabilities on the quality of customer service process in Iranian insurance companies.

Iran located in Middle East region and has 1.6 million $\mathrm{Km}^{2}$ area with more than 70 million people and a wide range of climatic conditions. With more than 7000 years of continuous civilization, Iran is endowed with numerous historical and cultural attractions. In addition, since Iran is allocated first among 105 important area for domestic, overwintering and breeding birds [26], it has suitable positions to introduce and attract the wildlife tourism industry.

The purpose of this research is based on strategic fuzzy assessment to environmental planning. Because of the wetlands importance and it sensitivity in face of changing, Bazangan lake was analyzed by all kinds of attractive to bird watch zoning. Base of it in this study, expressing purposes emphasized on strategic pattern of fuzzy assessment and provided short and medium terms strategies base on SWOT matrix. Provided Results were based on sustainable development and it can determine the best strategies for referring suitable areas of wildlife tourism. Also, this study can provide appropriate management strategies base on fuzzy assessment to future of Bazangan Lake and even for every lake in general.

\section{Materials and Methods}

\subsection{Study Area}

Bazangan Lake is national natural heritage in Iran and the largest natural Lake in nor- 
thern east of Iran which it located in close to Sarakhs in geographical coordinates $36^{\circ} 19^{\prime} 6^{\prime \prime}$ to $36^{\circ} 18^{\prime} 36^{\prime \prime} \mathrm{N}$ and $60^{\circ} 29^{\prime} 5^{\prime \prime}$ to $60^{\circ} 28^{\prime} 32 \mathrm{E} \mathrm{E}$ (e.g. Figure 1 ). Total study area is 4331 ha that include 320 ha water body and its average elevation is $850 \mathrm{~m}$ a.s.l. Bazangan climate is generally semi-arid. In according to the MW (Mediterranean wetlands) and Ramsar classifications this lake is classified in LW (Lacustrine wetland) class and Q group that include permanent brackish and saline lakes, respectively [27]. In addition, this Lake is important habitat for birds for overwintering and Breeding [28]. For understanding of present study level, a framework by describing steps of study is brought in Figure 2.

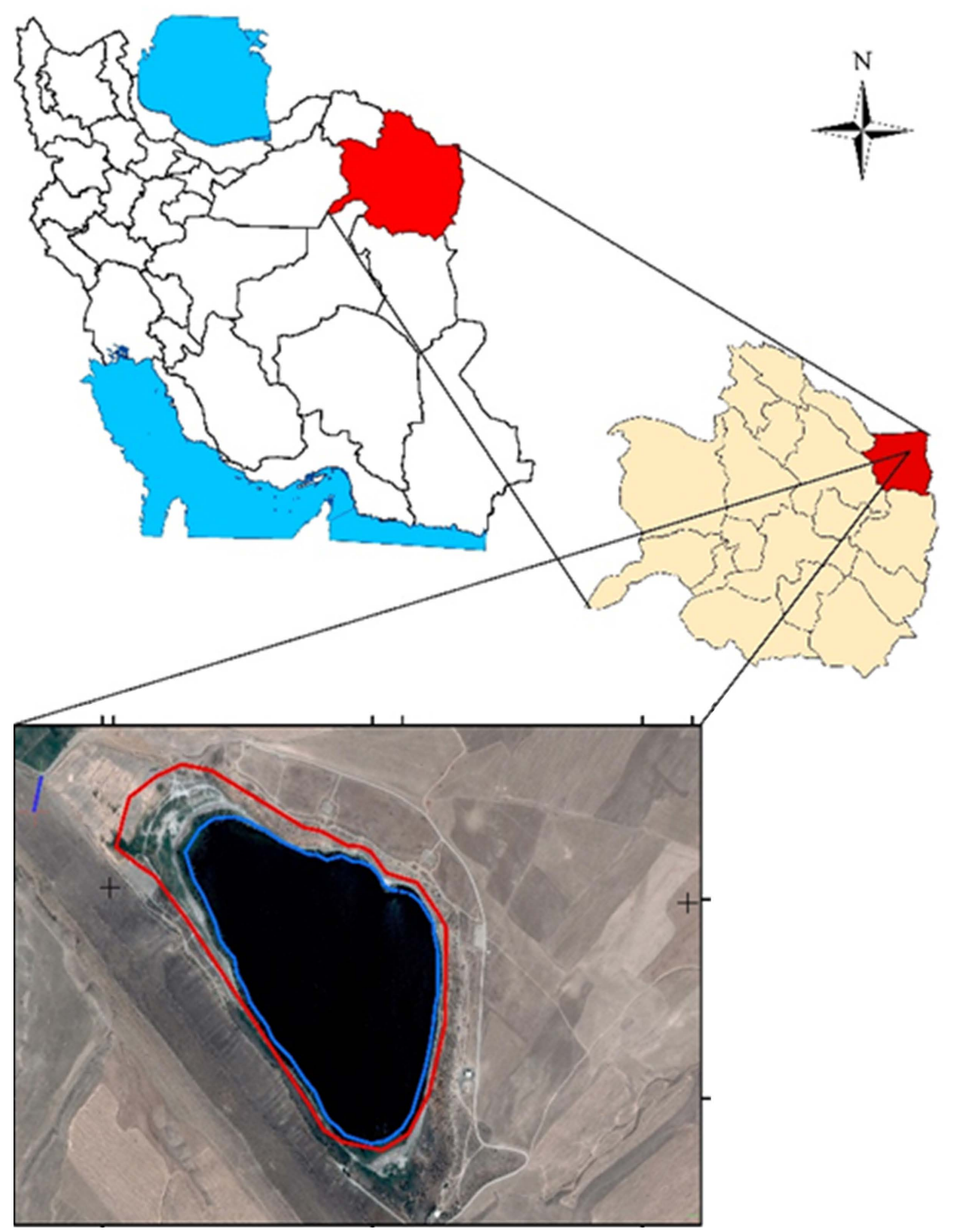

Figure 1. Location of Lake Bazangan in Khorasan Razavi province. 


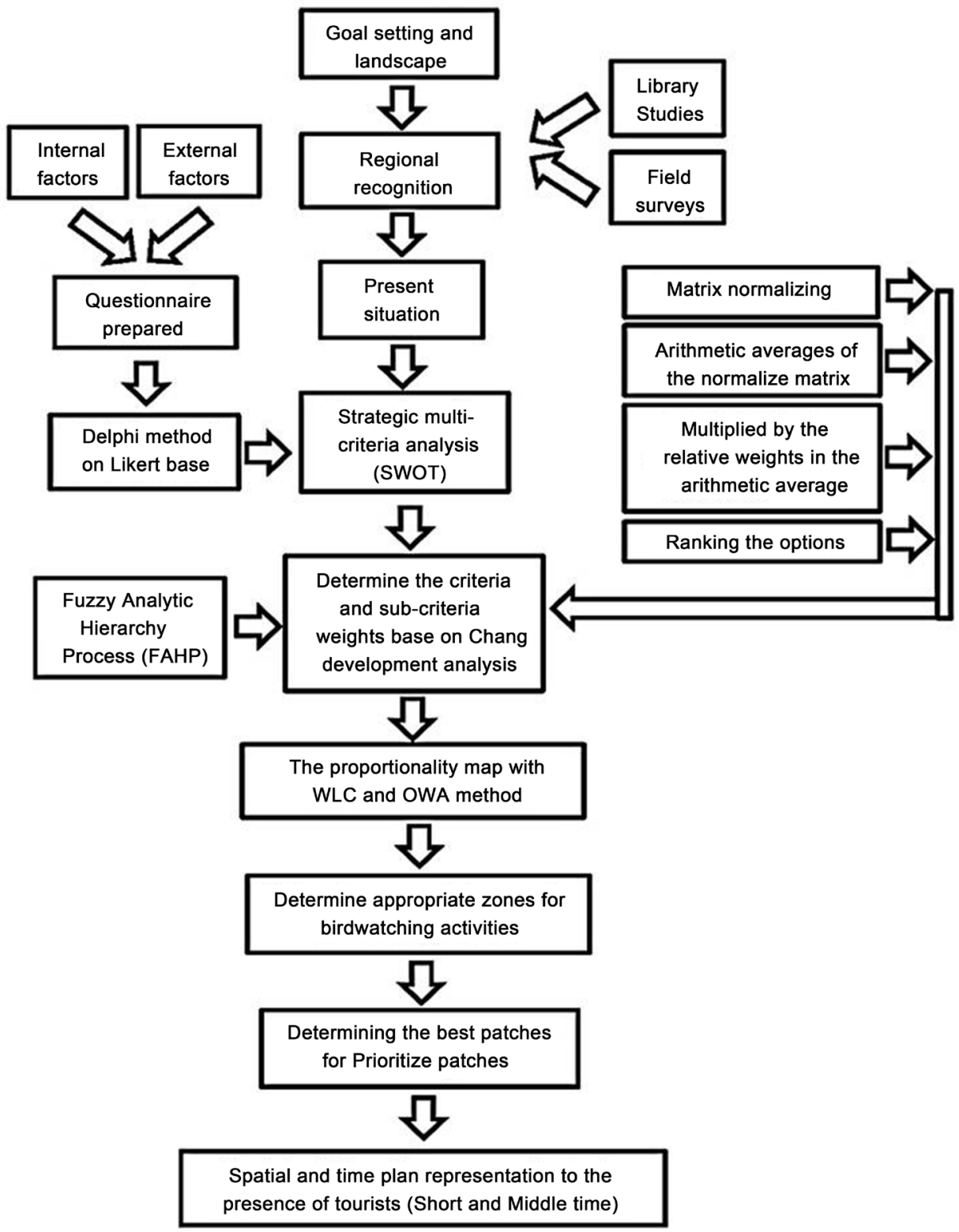

Figure 2. A framework by describing steps of present study.

\subsection{Determining the Appropriate Strategies and Sites for Bazangan Lake Wildlife Tourism}

In this study, a combination of SWOT strategic analysis and FAHP was used to make strategic management perspective of wildlife tourism in Bazangan Lake to reach strategic fuzzy assessment.

By literature review and interviews, the strengths, weaknesses, opportunities and threats factors as well their preference were assigned and categorized [29] [30] [31]. After screening on selected SWOT factors, pair wise comparisons are carried out separately by questionnaire base on FAHP model. These comparisons were happened within each SWOT group on Likert scale that is showed in Table 1. The TFNs (Triangular 
Table 1. Linguistic variables for triangular fuzzy number base on this study (Chen \& Hwang, 1992).

\begin{tabular}{ccc}
\hline Linguistic variables & Triangular fuzzy numbers & Reciprocal triangular fuzzy numbers \\
\hline Exactly equal important & $(1,1,1)$ & $(1,1,1)$ \\
Very low important & $(1 / 2,1,3 / 2)$ & $(2 / 3,1,2)$ \\
Low important & $(1,3 / 2,2)$ & $(1 / 2,2 / 3,1)$ \\
Medium important & $(3 / 2,2,5 / 2)$ & $(2 / 5,1 / 2,2 / 3)$ \\
High important & $(2,5 / 2,3)$ & $(1 / 3,2 / 5,1 / 2)$ \\
Very High important & $(5 / 2,2,7 / 2)$ & $(2 / 7,1 / 3,2 / 5)$ \\
\hline
\end{tabular}

fuzzy number) used in the pair-wise comparison are defined by three real numbers expressed as a triple $(\mathrm{l}, \mathrm{m}, \mathrm{u})$ where $\mathrm{l} \leq \mathrm{m} \leq \mathrm{u}$ for describing the fuzzy logic.

After determining the weight of each factor in each questionnaire, geometric average of them were calculated (to reduce errors and increase reliability) and the scores which they were higher than the average, identified as the most important factors. In other to this, the relative importance weights of evaluation criteria were calculated by FAHP based on Table 1 that is one of the commonly used preferences scale [32].

Alternatives (regional spots) suitable zones for bird watching which they were obtained by SWOT analysis were calculated by WLC (Weighted Linear Combination) and OWA (Ordered Weighting Averaging) methods. To ensure the applicability of the WLC model for other similar areas and situations, OWA methods was applied by changing in its global weights. More ever of applying the basic weights in Weighted Linear Combination (WLC), ranking weights are also applied in OWA method.

In addition, sensitivity analysis has been done by alteration in input sub factors and their relative importance weights. Results of comparison among different applying global weights and sensitivity analysis on suitable area for bird watching are presented in this study that help to judge on the basis of changes in WLC and OWA results. If the result will be same this method is beneficial for strategic fuzzy assessment and it can use in other area for wildlife zoning too (Figure 2).

On the base of regional circumstances and interactions between factors, triangular fuzzy numbers were used to calculate fuzzy weights for this study base on doing studies like [33]. The process of weights and consistency ratio calculating are summarized in below five steps [34].

The first step: Table 1 was used to develop a fuzzy composite on each objective. As mentioned, the TFNs which they used in the pair-wise comparison are defined by three real numbers expressed as a triple $(1, \mathrm{~m}, \mathrm{u})$ where $\mathrm{l} \leq \mathrm{m} \leq \mathrm{u}$ are brought for describing the fuzzy logic. Fuzzy values $\left(A_{g i}^{1}, A_{g i}^{2}, \ldots, A_{g i}^{m}\right)$ are calculated for I object of $m$ ideal that is described in Equation 1 [35] [36].

Equation 1: $S_{i}=\sum_{i=1}^{m} A_{g i}^{j} \times\left[\sum_{i=1}^{n} \sum_{i=1}^{m} A_{g i}^{j}\right]^{-1}$

The second step: This stage involved determining the degree of preference for two 
fuzzy numbers (Si vs. SK). To determine the degree of preference, Equation 2 is used to calculate the minimum amount for each computation [37] [38].

Equation 2: $V\left(S_{i} \geq S_{k}\right)=S U P_{x \geq y}\left(\min \left\{\alpha_{S_{i}}^{(x)}, \alpha_{S_{k}}^{(y)}\right\}\right)$

In this step, for determining the minimum amount, the Equation 3 was used. As shown in (e.g. Figure 3) [39], the value of $d$ is the biggest point between $\alpha_{S_{k}}$ and $\alpha_{S_{i}}$ that demonstrate a minimum of two fuzzy numbers.

Equation 3: $V\left(S_{i} \geq S_{k}\right)=\alpha_{S_{i}}(d)=\left[\begin{array}{cc}1 & \text { if }\left(m_{i} \geq m_{k}\right) \\ 0 & \text { if }\left(l_{k} \geq u_{i}\right) \\ \frac{l_{k}-u_{i}}{\left(m_{i}-u_{i}\right)-\left(m_{k}-l_{k}\right)} & \text { Otherwise }\end{array}\right]$

The third step: To determine the degree of priority and feasibility of a convex fuzzy number $(\mathrm{S})$ that is greater than convex fuzzy number $\mathrm{k}(\mathrm{Si})$, Equation 4 was assisted to calculate fuzzy weights vector (Equation 5) [40] [41]. This equation can help to reach fuzzy assessment base of strategic purposes.

Equation 4: $i=1,2, \ldots, k$

$$
\begin{aligned}
& V\left(S \geq S_{1}, S_{2}, \cdots, S_{k}\right)=V\left(\left(S \geq S_{1}\right), \cdots,\left(S \geq S_{k}\right)\right) \\
& =\min \left(V\left(S \geq S_{1}\right), V\left(S \geq S_{2}\right), \cdots, V\left(S \geq S_{k}\right)\right)=\min V\left(S \geq S_{i}\right)=d^{\prime}\left(A_{i}\right)
\end{aligned}
$$

Equation 5: $W^{\prime}=\left(d^{\prime}\left(A_{1}\right), d^{\prime}\left(A_{2}\right), \ldots, d^{\prime}\left(A_{n}\right)\right)$

The fourth step: To have crisp weights vector, $\mathrm{W}^{\prime}$ vector was converted for defuzzification weights vector (W) (Equation 6).

Equation 6: $W=\left(d\left(A_{1}\right), d\left(A_{2}\right), \ldots, d\left(A_{n}\right)\right)$

Finally, in the fifth step to ensure the each paired comparison compatibility, CR (Consistency Ratio) was calculated. For this purpose, instruction of classical AHP and equal crisp number of each fuzzy number (e.g. Table 1) was applied that is referred by [42] [43] [44] [45].

\section{Sensitivity Analysis}

Sensitivity analyses are valuable tools for identifying important parameters of model

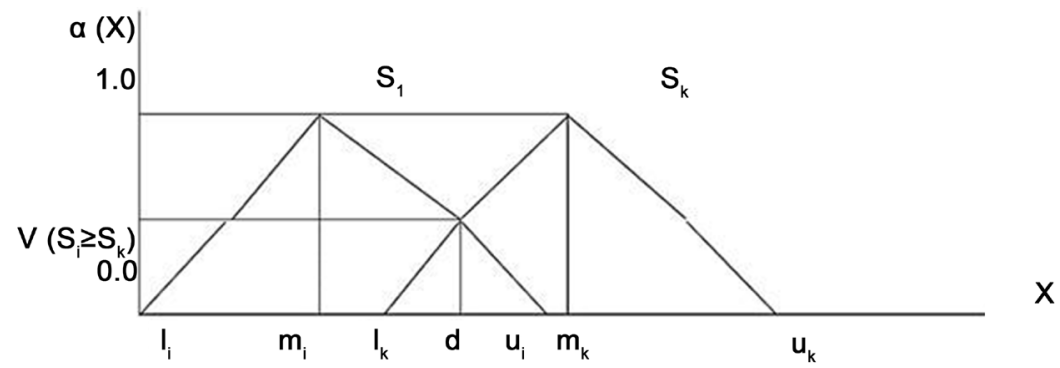

Figure 3. D point position between $\mathrm{S}_{\mathrm{k}} \alpha$ and $\mathrm{S}_{\mathrm{i}} \alpha$ (Zhu, K. et al., 1999). 
that it is referred by [46] [47] [48] [49] [50]. Among all categories of risks, the operational risk category receives the highest priority weight. Therefore, it is capable enough to influence the other categories of risk. Based on the study of [28] suggested that small changes in relative weights would give large changes in the final ranking [28]. As, human judgment input is utilized to calculate the weights for the listed categories of risks and specific risks, thereby, it is recommended to test the final ranking by varying the weights of all the categories of risks [32] [33].

It is important to recall that, when using FAHP for criteria weighting, a consistency ratio (CR) is obtained in addition to the corresponding principal eigenvector, which represents the priority vector, integrated by the intended weights [35] [36] [37]. According to [38] [39] studies that they applied sensitivity analyses, this analysis is useful for testing the model conceptualization and improving the model structure [25] [51]. Sensitivity analysis indicates the validity of the applied method and its capability to use in other similar situations [52]. In this study, the sensitivity analysis was done by different sets of factors, sub factors, changing in the number of maps classes and their range. Results of this method can determine capability of presented model for applying in other areas.

\section{Results}

Based on the SWOT analysis, sub factors for weakness, strength, opportunity and threat were obtained (e.g. Figure 4). By investigation of correlation of sub factors and their importance, a classified list of sub factors was prepared. In total, 16 sub factors were selected that included five strengths, four weaknesses, three opportunities and four threats (e.g. Table 2). On the base of Table 1, these comparisons are happened within each SWOT group on Likert scale that it showed in Table 3. These sub factors have

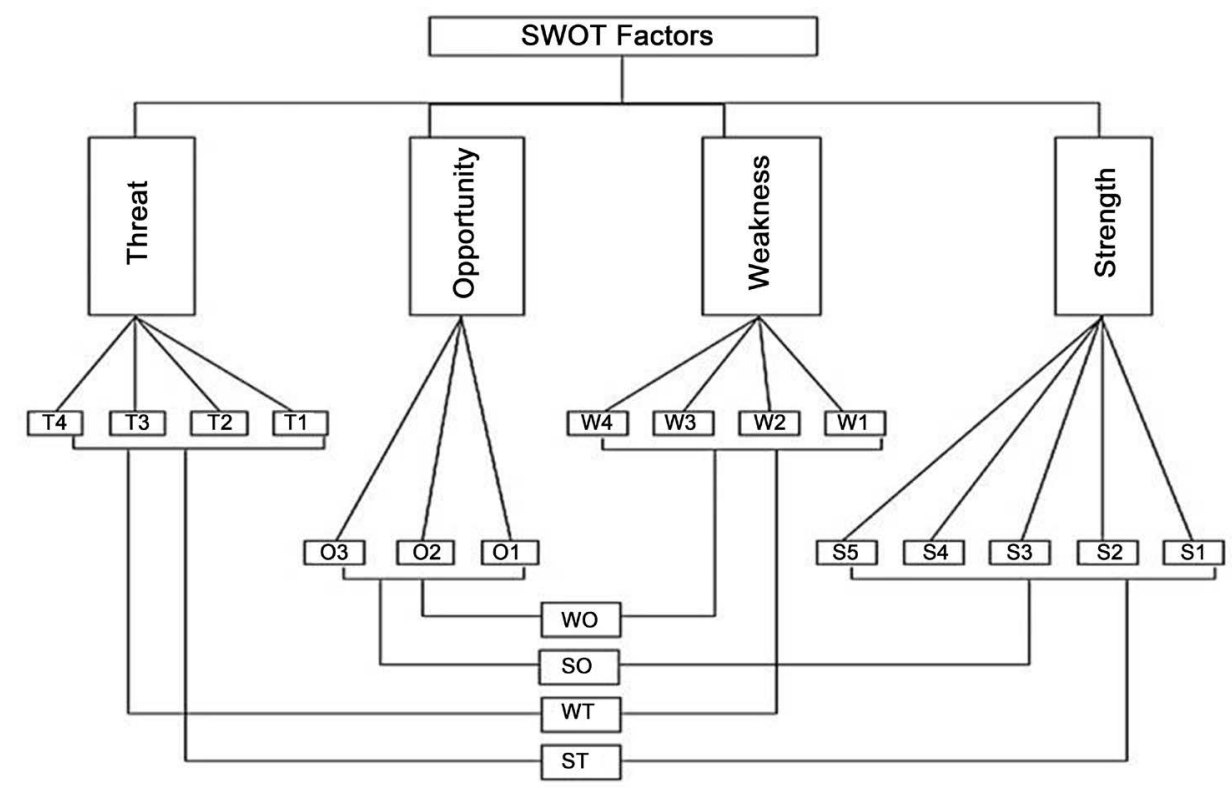

Figure 4. Hierarchical structure of selected factors and sub-factors and SWOT factors strategies. 
Table 2. Strengths, weaknesses, opportunities and threats factors.

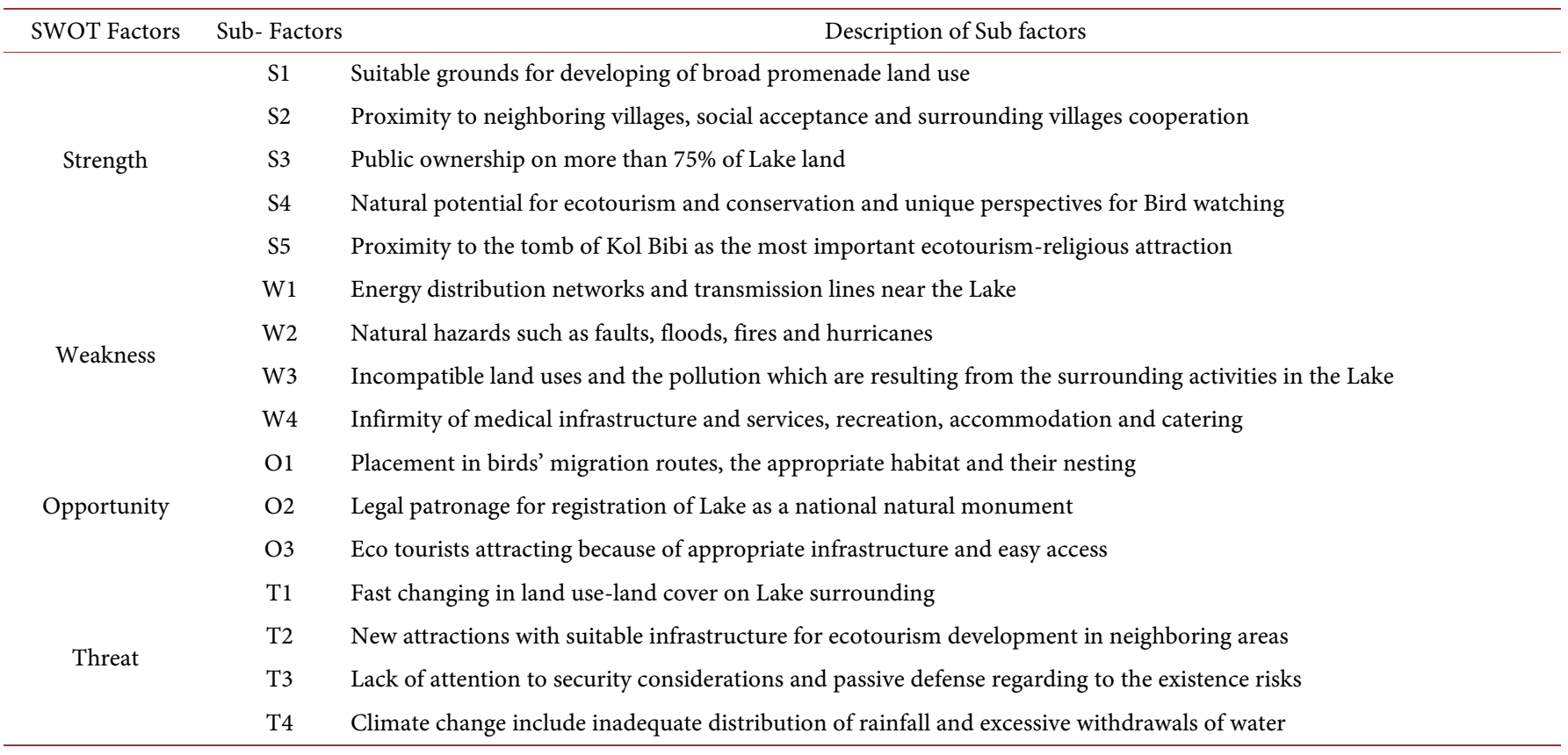

Table 3. Paired comparisons of SWOT factors and sub-factors.

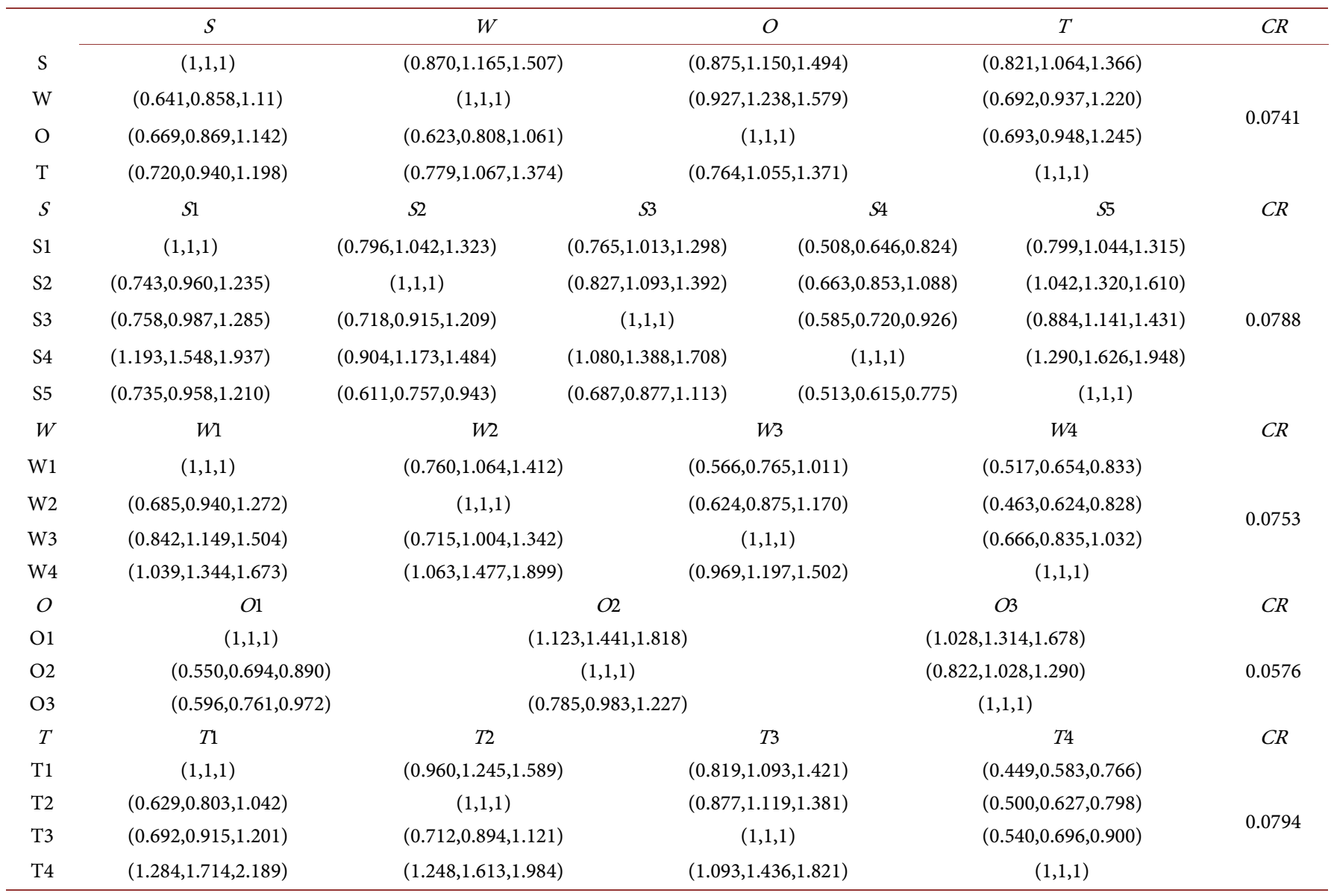


significant effect on the bird watching tourists and wildlife tourism at Bazangan Lake. The preference values among SWOT factors, sub factors and their normalized weights are presented in Table 4.

Relative importance weights of SWOT factors and sub factors that were calculated by FAHP method (under paired comparison), are presented in Table 5. Also, consistency Ratio (CR) for each factor and sub factor was evaluated that amount of it was less than 0.1 for all of comparisons. Therefore the accuracy of the compatibility in paired comparisons was valid (e.g. Table 3).

To compare the strengths, weaknesses, opportunities and threats and determine their preferences, for better understanding of the area condition, results of SWOT analysis and FAHP method were integrated by [53] procedure that is offered better visual comparison (e.g. Figure 5).

Additionally, Figure 6 illustrates matrix of internal and external factors which it can be used to judge about situation for bird watching in this area. Also, strategies for the short and medium terms were obtained for strategic fuzzy assessment and bird watching planning in Table 6 precisely. In this table, strategies are created by SWOT factors and sub factors which they are mentioned at each line.

Table 4. Calculation of amount of preference in SWOT factors and achieve to the minimum count with normalize weights.

\begin{tabular}{|c|c|c|}
\hline SWOT & \multicolumn{2}{|c|}{$\mathrm{S}$} \\
\hline $\mathrm{V}(\mathrm{S} \geq \mathrm{W})=1$ & $\mathrm{~V}\left(\mathrm{~S}_{1} \geq \mathrm{S}_{2}\right)=0.878$ & $\mathrm{~V}\left(\mathrm{~S}_{4} \geq \mathrm{S}_{2}\right)=1$ \\
\hline $\mathrm{V}(\mathrm{W} \geq \mathrm{S})=0.9$ & $\mathrm{~V}\left(\mathrm{~S}_{2} \geq \mathrm{S}_{1}\right)=1$ & $\mathrm{~V}\left(\mathrm{~S}_{2} \geq \mathrm{S}_{5}\right)=1$ \\
\hline $\mathrm{V}(\mathrm{S} \geq \mathrm{O})=1$ & $\mathrm{~V}\left(\mathrm{~S}_{1} \geq \mathrm{S}_{3}\right)=0.995$ & $\mathrm{~V}\left(\mathrm{~S}_{5} \geq \mathrm{S}_{2}\right)=0.718$ \\
\hline $\mathrm{V}(\mathrm{O} \geq \mathrm{S})=0.772$ & $\mathrm{~V}\left(\mathrm{~S}_{3} \geq \mathrm{S}_{1}\right)=1$ & $\mathrm{~V}\left(\mathrm{~S}_{1} \geq \mathrm{S}_{2}\right)=0.878$ \\
\hline $\mathrm{V}(\mathrm{T} \geq \mathrm{S})=0.909$ & $\mathrm{~V}\left(\mathrm{~S}_{1} \geq \mathrm{S}_{4}\right)=0.555$ & $\mathrm{~V}\left(\mathrm{~S}_{3} \geq \mathrm{S}_{4}\right)=0.569$ \\
\hline $\mathrm{V}(\mathrm{S} \geq \mathrm{T})=1$ & $\mathrm{~V}\left(\mathrm{~S}_{4} \geq \mathrm{S}_{1}\right)=1$ & $\mathrm{~V}\left(\mathrm{~S}_{4} \geq \mathrm{S}_{3}\right)=1$ \\
\hline $\mathrm{V}(\mathrm{O} \geq \mathrm{W})=0.873$ & $\mathrm{~V}\left(\mathrm{~S}_{1} \geq \mathrm{S}_{5}\right)=1$ & $\mathrm{~V}\left(\mathrm{~S}_{3} \geq \mathrm{S}_{5}\right)=1$ \\
\hline $\mathrm{V}(\mathrm{W} \geq \mathrm{O})=1$ & $\mathrm{~V}\left(\mathrm{~S}_{5} \geq \mathrm{S}_{1}\right)=0.845$ & $\mathrm{~V}\left(\mathrm{~S}_{5} \geq \mathrm{S}_{3}\right)=0.838$ \\
\hline $\mathrm{V}(\mathrm{T} \geq \mathrm{W})=1$ & $\mathrm{~V}\left(\mathrm{~S}_{2} \geq \mathrm{S}_{3}\right)=1$ & $\mathrm{~V}\left(\mathrm{~S}_{4} \geq \mathrm{S}_{5}\right)=1$ \\
\hline $\mathrm{V}(\mathrm{W} \geq \mathrm{T})=0.991$ & $\mathrm{~V}\left(\mathrm{~S}_{3} \geq \mathrm{S}_{2}\right)=0.886$ & $\mathrm{~V}\left(\mathrm{~S}_{5} \geq \mathrm{S}_{4}\right)=0.389$ \\
\hline $\mathrm{V}(\mathrm{T} \geq \mathrm{O})=1$ & $\mathrm{~V}\left(\mathrm{~S}_{2} \geq \mathrm{S}_{4}\right)=0.678$ & \\
\hline \multicolumn{3}{|l|}{$\mathrm{V}(\mathrm{O} \geq \mathrm{T})=0.865$} \\
\hline $\min V\left(S_{1} \geq S_{k}\right)=0.389$ & \multicolumn{2}{|c|}{$\min V\left(S_{i} \geq S_{k}\right)=0.772$} \\
\hline $\mathrm{W}$ & $\mathrm{O}$ & $\mathrm{T}$ \\
\hline $\mathrm{V}(\mathrm{W} 1 \geq \mathrm{W} 2)=1$ & $\mathrm{~V}(\mathrm{O} 1 \geq \mathrm{O} 2)=1$ & $\mathrm{~V}(\mathrm{~T} 1 \geq \mathrm{T} 2)=1$ \\
\hline $\mathrm{V}(\mathrm{W} 2 \geq \mathrm{W} 1)=0.985$ & $\mathrm{~V}(\mathrm{O} 2 \geq \mathrm{O} 1)=0.868$ & $\mathrm{~V}(\mathrm{~T} 2 \geq \mathrm{T} 1)=0.881$ \\
\hline $\mathrm{V}(\mathrm{W} 1 \geq \mathrm{W} 3)=0.838$ & $\mathrm{~V}(\mathrm{O} 1 \geq \mathrm{O} 3)=1$ & $\mathrm{~V}(\mathrm{~T} 1 \geq \mathrm{T} 3)=1$ \\
\hline $\mathrm{V}(\mathrm{W} 3 \geq \mathrm{W} 1)=1$ & $\mathrm{~V}(\mathrm{O} 3 \geq \mathrm{O} 1)=0.743$ & $\mathrm{~V}(\mathrm{~T} 3 \geq \mathrm{T} 1)=0.864$ \\
\hline $\mathrm{V}(\mathrm{W} 1 \geq \mathrm{W} 4)=0.556$ & $\mathrm{~V}(\mathrm{O} 2 \geq \mathrm{O} 3)=1$ & $\mathrm{~V}(\mathrm{~T} 1 \geq \mathrm{T} 4)=0.560$ \\
\hline $\mathrm{V}(\mathrm{W} 4 \geq \mathrm{W} 1)=1$ & $\mathrm{~V}(\mathrm{O} 3 \geq \mathrm{O} 2)=0.999$ & $\mathrm{~V}(\mathrm{~T} 4 \geq \mathrm{T} 1)=1$ \\
\hline $\mathrm{V}(\mathrm{W} 2 \geq \mathrm{W} 3)=0.827$ & & $\mathrm{~V}(\mathrm{~T} 2 \geq \mathrm{T} 3)=1$ \\
\hline $\mathrm{V}(\mathrm{W} 3 \geq \mathrm{W} 2)=1$ & & $\mathrm{~V}(\mathrm{~T} 3 \geq \mathrm{T} 2)=0.985$ \\
\hline $\mathrm{V}(\mathrm{W} 2 \geq \mathrm{W} 4)=0.551$ & & $\mathrm{~V}(\mathrm{~T} 2 \geq \mathrm{T} 4)=0.425$ \\
\hline $\mathrm{V}(\mathrm{W} 4 \geq \mathrm{W} 2)=1$ & & $\mathrm{~V}(\mathrm{~T} 4 \geq \mathrm{T} 2)=1$ \\
\hline $\mathrm{V}(\mathrm{W} 3 \geq \mathrm{W} 4)=0.723$ & & $\mathrm{~V}(\mathrm{~T} 3 \geq \mathrm{T} 4)=0.400$ \\
\hline $\mathrm{V}(\mathrm{W} 4 \geq \mathrm{W} 3)=1$ & & $\mathrm{~V}(\mathrm{~T} 4 \geq \mathrm{T} 3)=1$ \\
\hline $\min V(S i \geq S k)=0.551$ & $\min \mathrm{V}(\mathrm{Si} \geq \mathrm{Sk})=0.743$ & $\min \mathrm{V}(\mathrm{Si} \geq \mathrm{Sk})=0.40 \mathrm{C}$ \\
\hline
\end{tabular}


Table 5. The relative weights of SWOT factors and sub-factors.

\begin{tabular}{|c|c|c|c|c|}
\hline Factors & Factors Weight & Sub-Factors & Local Sub-Factors Weight & Overall Sub-Factors Weight \\
\hline \multirow{5}{*}{ Strengths } & \multirow{5}{*}{0.28} & S1 & 0.174 & 0.049 \\
\hline & & S2 & 0.212 & 0.059 \\
\hline & & S3 & 0.178 & 0.050 \\
\hline & & S4 & 0.313 & 0.088 \\
\hline & & S5 & 0.122 & 0.034 \\
\hline \multirow{4}{*}{ Weaknesses } & \multirow{4}{*}{0.25} & W1 & 0.196 & 0.049 \\
\hline & & W2 & 0.195 & 0.049 \\
\hline & & W3 & 0.256 & 0.064 \\
\hline & & W4 & 0.353 & 0.089 \\
\hline \multirow{3}{*}{ Opportunities } & \multirow{3}{*}{0.22} & $\mathrm{O} 1$ & 0.383 & 0.083 \\
\hline & & $\mathrm{O} 2$ & 0.332 & 0.072 \\
\hline & & $\mathrm{O} 3$ & 0.285 & 0.061 \\
\hline \multirow{4}{*}{ Threats } & \multirow{4}{*}{0.25} & $\mathrm{~T} 1$ & 0.235 & 0.060 \\
\hline & & $\mathrm{T} 2$ & 0.178 & 0.045 \\
\hline & & T3 & 0.168 & 0.043 \\
\hline & & $\mathrm{T} 4$ & 0.419 & 0.106 \\
\hline
\end{tabular}

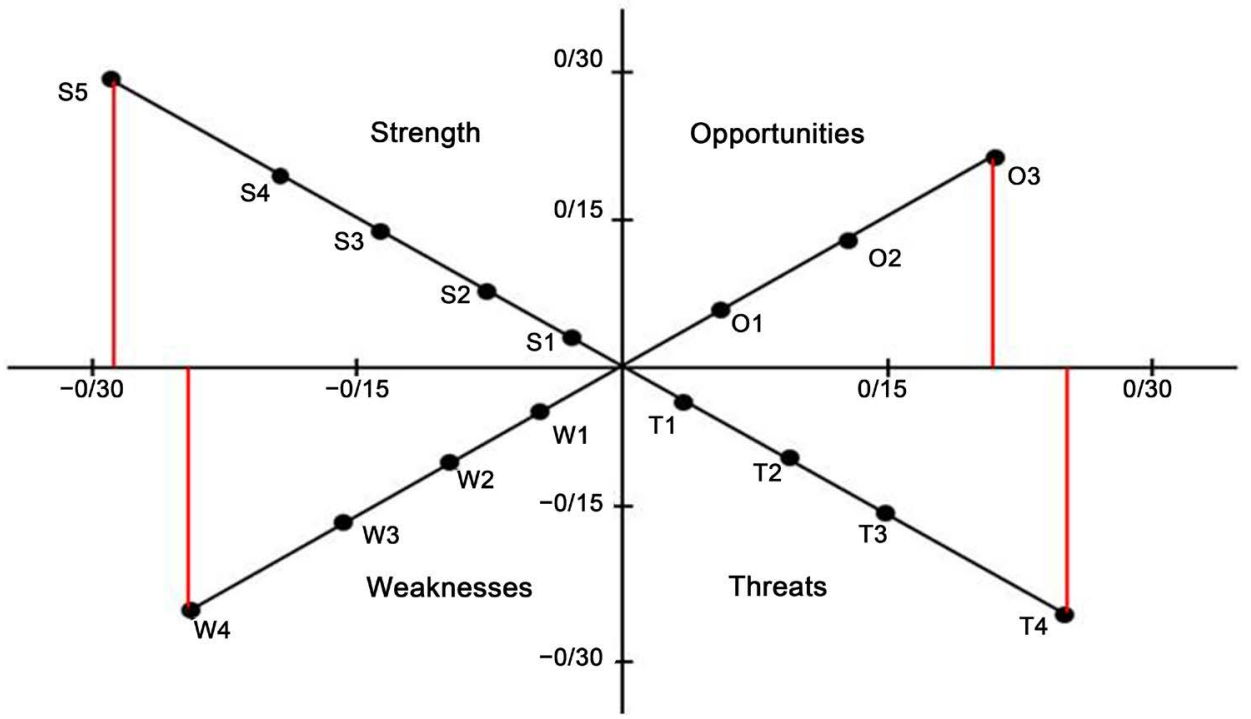

Figure 5. Paired comparisons of SWOT factors and sub-factors on Kurttila procedure (Kurttila, et al., 2000)

\section{Determining Suitable Area for Bird Watching}

Suitable area for bird watching was obtained by WLC method which was used to combine standardized maps in according to hierarchical decision structure (e.g. Figure 4) and relative importance weights. Some of important SWOT sub factors maps and final 


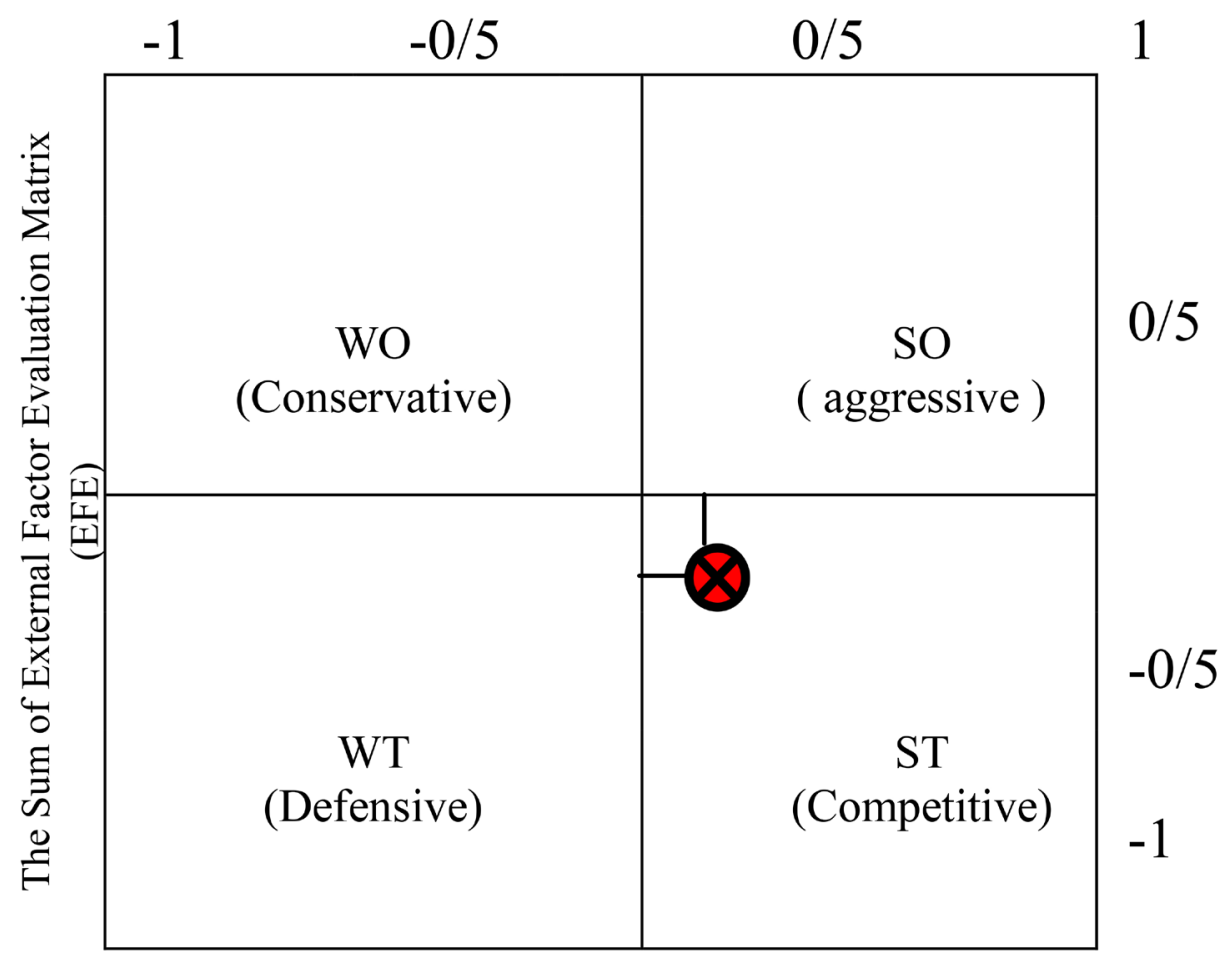

\section{The Sum of Internal Factor Evaluation Matrix (IFE)}

Figure 6. Matrix of internal and external factors for bird watching in the study area.

Table 6. Short and medium terms strategies base on SWOT matrix.

\section{Presented Strategies}

WO Local community participation in nature based tourism development (O1, O3, W3, W4)

(Conservative) Developing a wetland management plan as one of the protected areas (O2, W3, W4)

(Mid-time) Restoration local communities to Ecotourism development (O1, O3, W4)

Competitive)

Restoration environment for increased resilience against environmental hazards (natural and human) (S2, T3, T4)

(Mid-time)

Stabilizing land use and prevent the conversion of land by virtual activities development (S1, S3, T1, T2)

SO

(aggressive)

(Short-time) Responsible Ecotourism development especially bird watching (S1, S2, S4, S5, T1, T2, T3)

Developing action plan bird watching base on management plan and Preparing monitoring system (S4, S5, O2, O3)

Consolidation of ecological surrounding of Lake by definition of precincts and land Stabilizing (S1, S3, O2)

Ecological promoting and restoration of Lake (S1, S4, S5, O1, O3)

Restoration local communities to participatory management of Lake (S2, S4, S5, O3)

maps are presented in Figure 7 and Figure 8 that they show standardized maps base on compatibility and suitability maps in WLC and OWA methods. Also, Table 7 showed determining algorithms for S4, W4, O1 and T4 SWOT factors for example base on Fuzzy method that Figure 7 and Figure 8 are made base on it. The relative importance weights of the factors and sub factors were calculated on the basis of Table 1 and using of Chang development analysis (e.g. Table 3 ).

The most important factor among of local sub factors and global sub factors (Overall sub factor) were $\mathrm{S} 4, \mathrm{~W} 4, \mathrm{O} 1$ and T4, respectively. Therefore, the ST condition is dominant in this study area because of the importance of strengths and amount of local and 
Table 7. Determining algorithms for SWOT factors base on Fuzzy method.

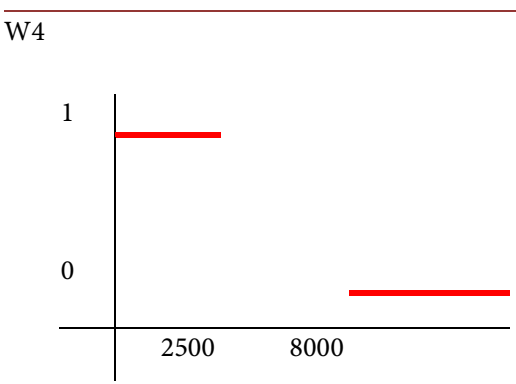

Deficiency of medical facilities

$\mathrm{T} 4$

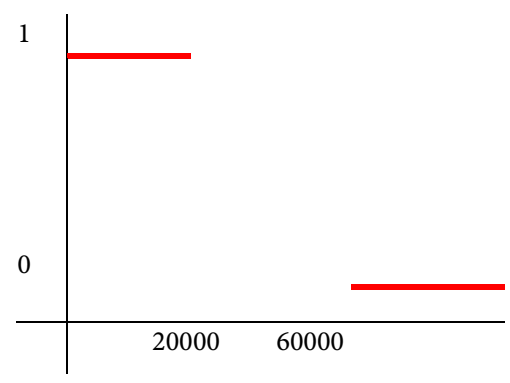

Influence of wind erosion critical section
S4

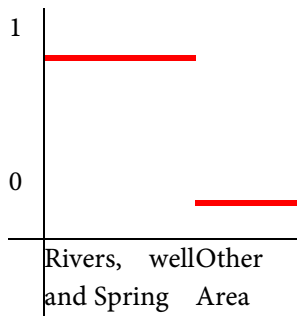

Priority for rivers, well and spring

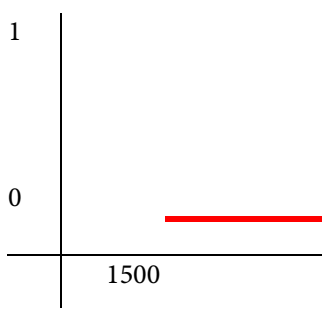

Priority for bird watching landscape
$\mathrm{O} 1$
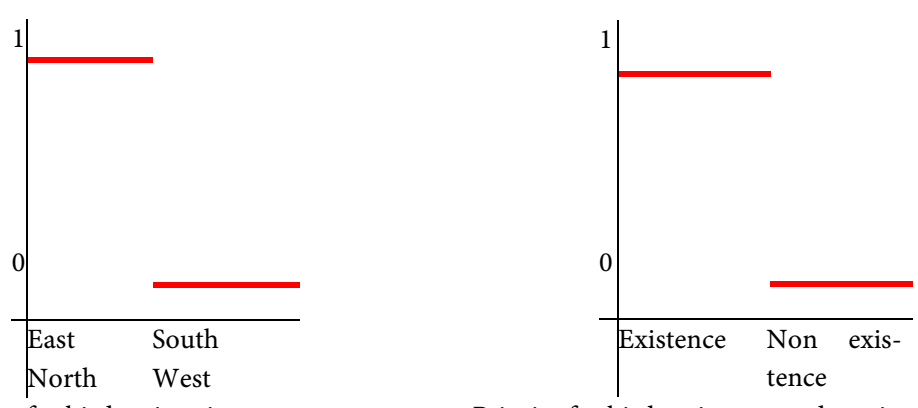

Priority for birds migration route

global weights for them.

In addition, sensitivity analysis was done by alteration in input sub factors and their relative importance weights. Results of comparison among applying global weights and sensitivity analysis by different weights on suitable areas for bird watching are presented in Figure 9 and Figure 10 that help to judge on the basis of changes in WLC result. Consistency Ratio (CR) for each factor and sub factor was evaluated that amount of it was less than 0.1 for all of comparisons. Therefore the accuracy of the compatibility in paired comparisons was valid (e.g. Table 3). In Figure 9, horizontal axis has determined amount of competence in the produced maps and horizontal axis in Figure 10 has determined amount of competence in the sensitivity analysis maps. Also, vertical axis in both of Figure 9 and Figure 10 was related to area changes in hectares.

\section{Discussion and Conclusion}

Since SWOT strategic analysis has been utilized more than other models in context of the environment particularly in the field of ecotourism [54] [55] [56], detecting of land use change [12], regional planning [18] [19] and the management plan in wetland and coastal areas, therefore SWOT analysis was used in this study to identify factors and sub factors for tourism activities with emphasizing on Bird watch zoning.

SWOT analysis with MCDM methods had been used in many researches like [15] [18] [23] [25] [29]. Results of the combination of SWOT and FAHP were showed which strategic conditions are determined by strengths and threats in this study area. In addition, by consideration affective internal and external factors, is revealed that the 


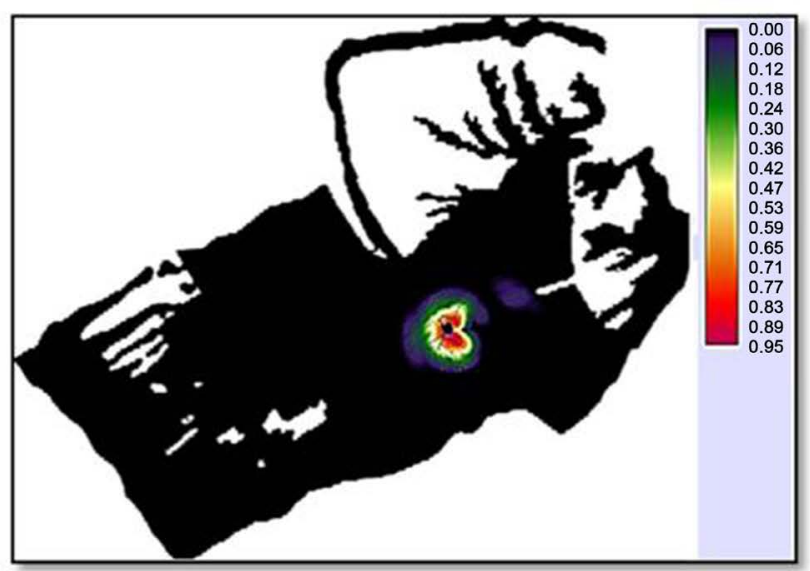

W4 factor

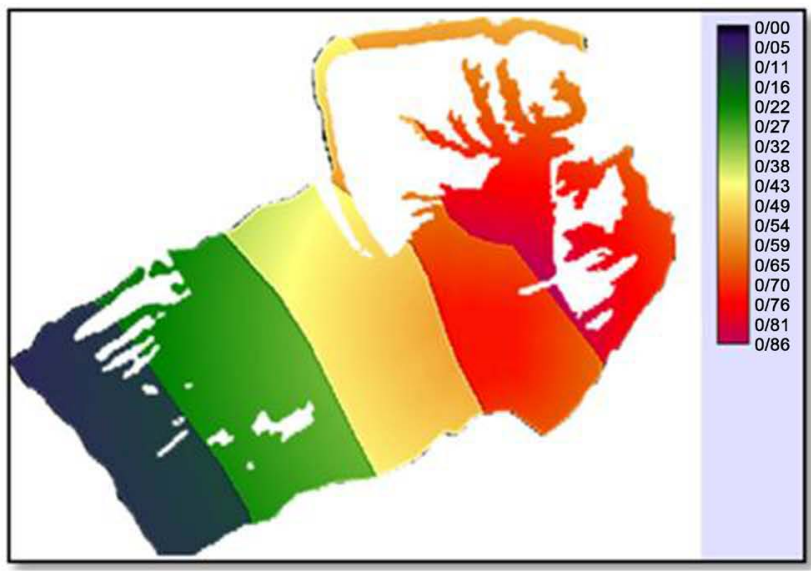

T4 factor

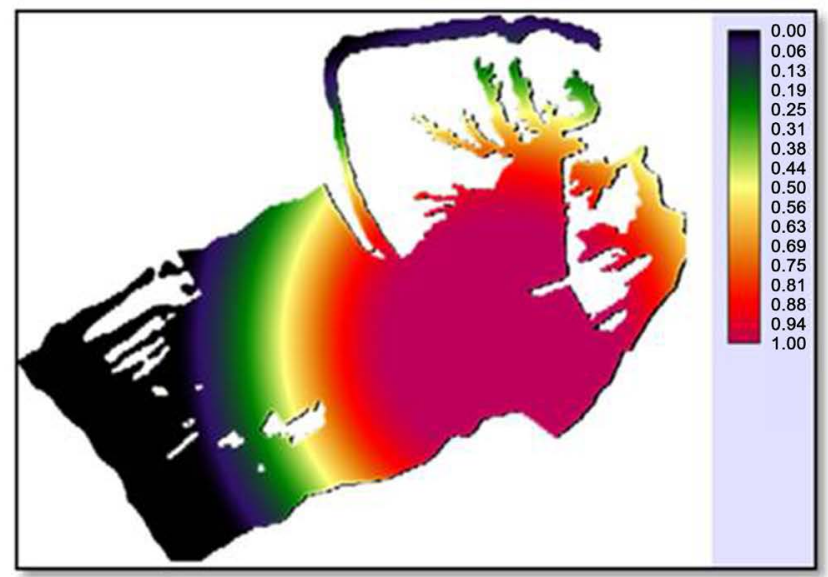

S4 factor

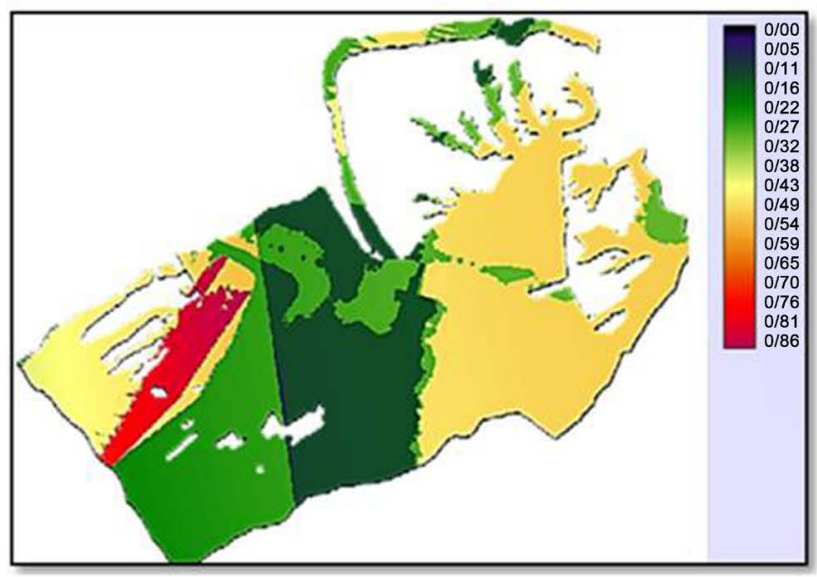

$\mathrm{O} 1$ factor

Figure 7. Standardized maps base on suitability.

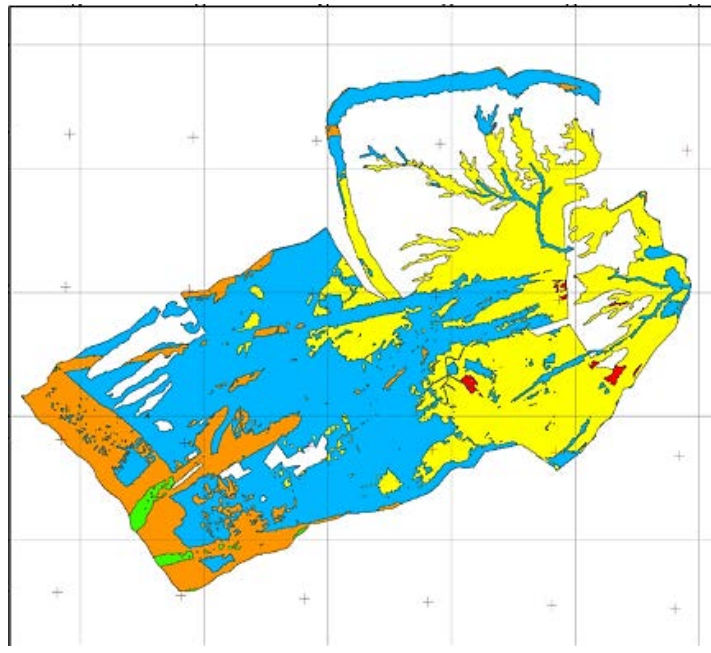

OWA method

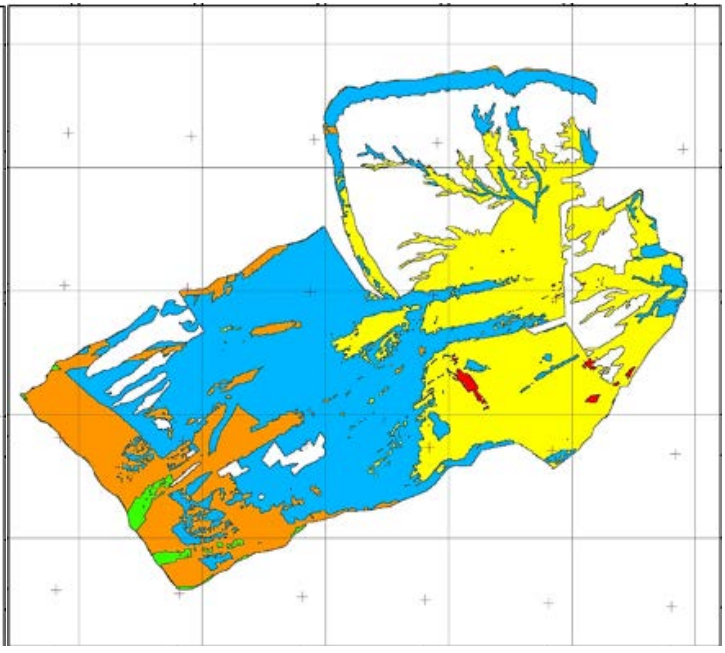

WLC method

Figure 8. Suitability maps in WLC and OWA methods. 


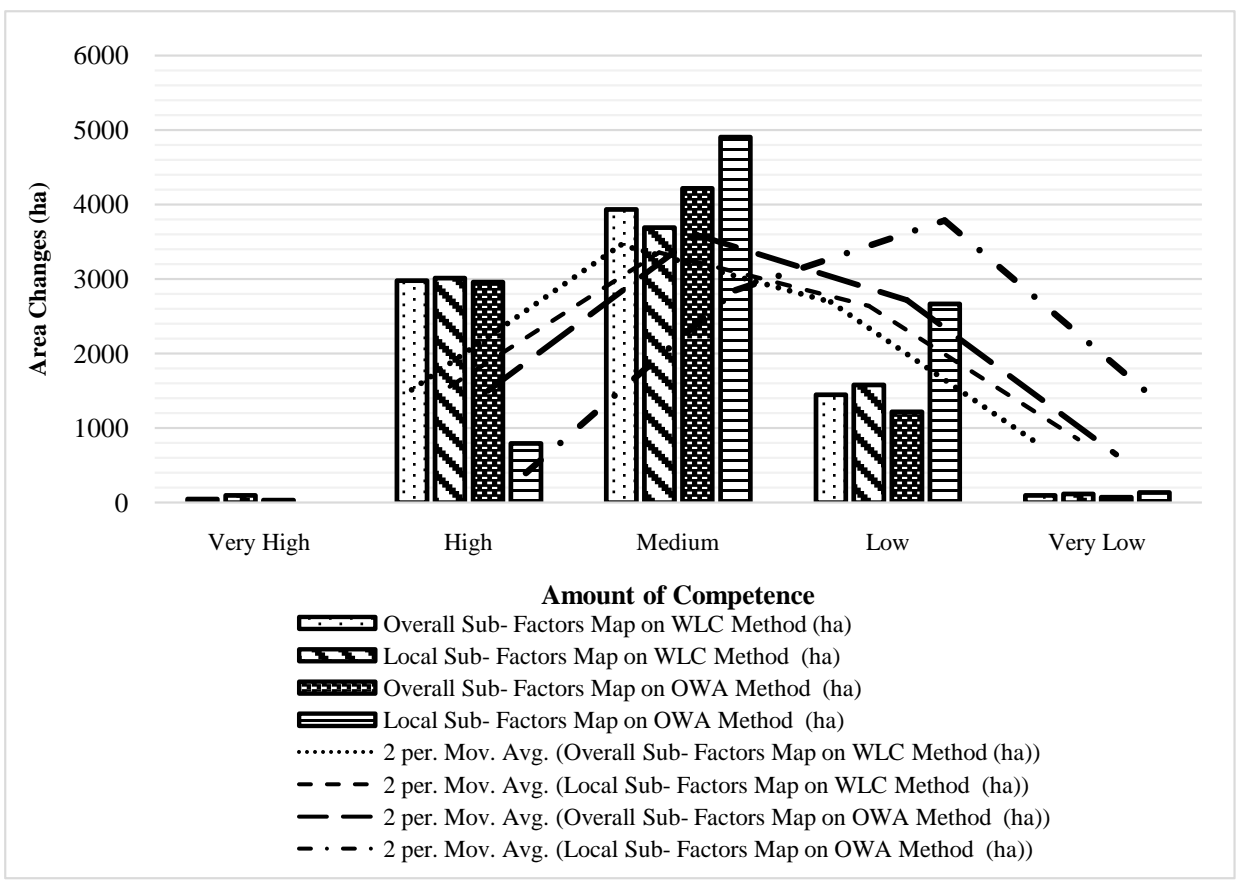

Figure 9. Comparison of changes in the area of competence in the produced maps.

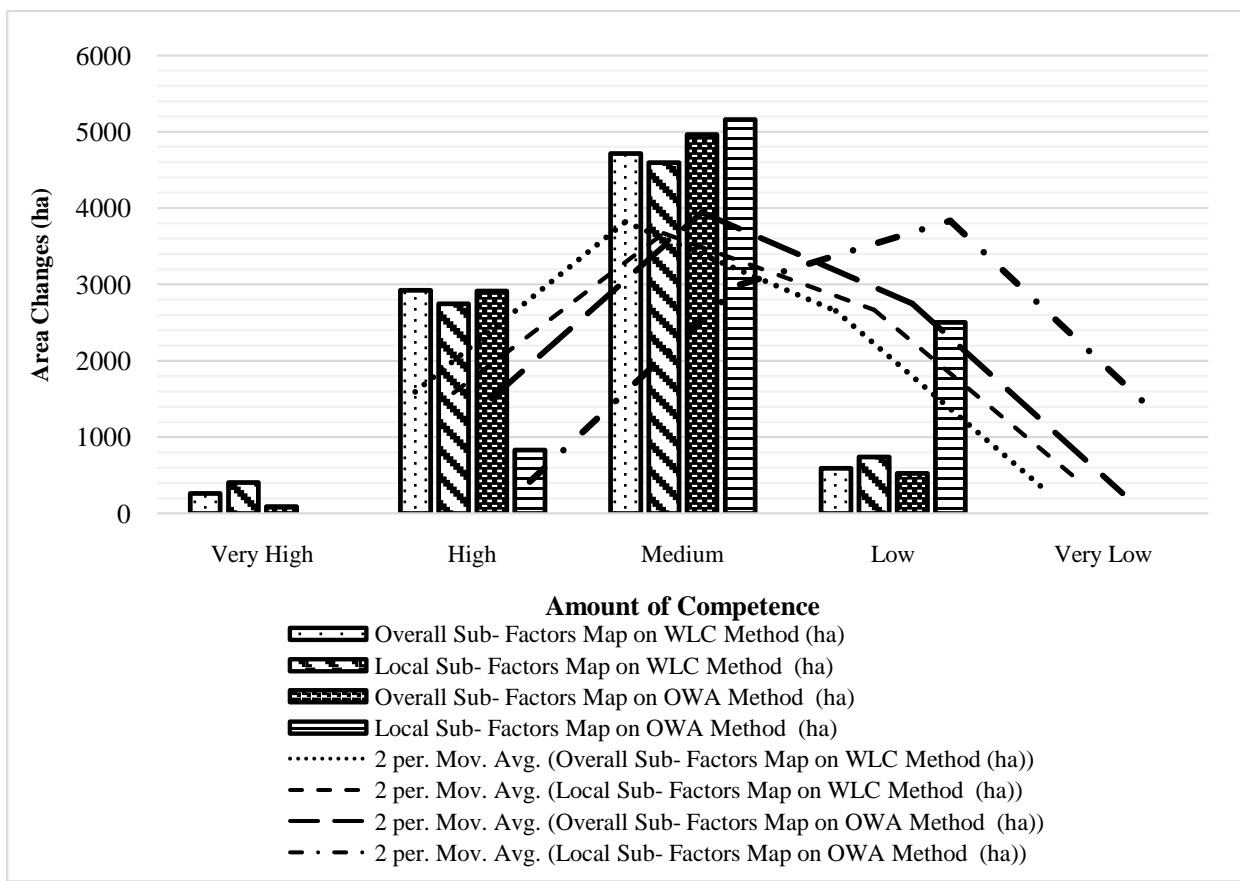

Figure 10. Comparison of changes in the area of competence in the sensitivity analysis maps.

competition condition) ST) in Bazangan Lake is dominant (e.g. Figure 6). Figure 5 is based on [25] that showed dominance of ST condition for Bazangan Lake. Also, comparison between Figures 5 and Figure 6 explained that using methodology in this study is valid too [25]. In this situation, some strategies should be determined which 
such as of them are conservative (WO), competitive (ST) and aggressive (SO) conditions in order that are presented in_Table 6.

In according to the political, social and economic situation medium (up to $10 \mathrm{yrs}$, conservative and competitive strategies) and short (up to 5 yrs. aggressive strategies) strategies terms can be selected as the best strategies and use for bird watching in Bazangan Lake (e.g. Table 6). Land use stabilizing and preventing the conversion of land by development of virtual activities and responsible ecotourism especially bird watchingstrategies in this research (Bazangan Lake) are compatible with [15] and [17] researches.

In spite of [15] [16] [17] results, in this research (Bazangan Lake) ST condition was calculated with mentioned analysis. The cause of it related to different conditions, manner of factors selecting and kind of factors for SWOT analysis. In according to the competitive conditions (ST) in Bazangan, suggested strategies must be included environment restoration to increase in environment resilience against hazards (natural and human), avoiding of land use and cover changes and having responsibly ecotourism development especially for Bird watching.

[30] has high harmony with obtained result. Also results of [42] are consistence with obtained results. They mentioned the high relative vulnerability threshold for tourism development planning in Bazangan Lake and it need to provide appropriate policies, monitoring, eliminate limitations, and consider the Lake capabilities and properties but they did not provide a detailed strategic plan as well as provided in the present study.

In this research, base of fuzzy assessment purposes, strategic decision led to a zoning plan for bird watching tourism. For making the maps of proportionality locations, strategic assessment was done correctly. The proportionality map which it was made by combination of sub factors (e.g. Figure 7), showed four zones with very high suitability values for bird watching activities (e.g. Figure 8).

All of the made maps were mixed under WLC and OWA methods for comparison; Alternatives in OWA methods were ranked (e.g. Figure 8). The final maps like Figure 8 that named suitability maps were provided in five classes. The classes of these maps were very high suitability, high suitability, medium suitability, low suitability and very low suitability. Provided classes on suitability maps can help for medium and short term strategic fuzzy assessment.

In this paper for innovating, set of mentioned methods are used to find suitable place for bird watching. As a result, the best locations for bird watching are in Sothern, Western and Eastern zones of Lake in preference order, therefore management plans should be occurred in this locations basis of the time limitations (seasons of a year). These spots can be used for different land use such as intensive and extensive bird watching activities.

Based on these provided results and comparison with other reference such as [53] [54] [55] [56], it understood from the suitability maps that the best places for bird watching were in southern and western slopes at the spring and summer in annual period. Suitable locations at the east of Lake were the best places in autumn and winter for 
wildlife tourism. These places not only provide less natural hazards threaten for people and environment, but also determine excellent conditions for birdwatcher and it activities annually. Following this, by presented medium and short terms strategies in ST, WO and SO conditions in Table 6, decision makers can be capable to plan base on presented strategies and they can program with attention to sustainable development theory.

Introduction and presence of tourists as a birdwatcher in these areas can provide many profits for the beneficiary communities. According the reality which making relation with local communities is presented in middle time strategies (e.g. Table 6), it needed to a training program to inform and empower local communities to wetlands partnership management by sharing them in the getting benefits in Bazangan Lake. With the implementation of this programs, the local people are able to understand about the values of the Lake and in other hand the local people with other people living in near villages and towns will depend economically to the Lake and they will attempt to improve the condition and situation of the Lake At last, the sensitivity analysis results did not show any difference within the results of the present study. Therefore, it is concluded that the obtained results are reliable and applied method is suitable to use for similar situations.

\section{Way Forward}

On one hand the results showed that the best process was selected for bird watchingzoning in Bazangan Lake and on the other hand, the method used in this study was suitable for susceptible areas especially for lakes and wetlands by strategic fuzzy multi criteria analysis. Also, sensitivity analysis was done by alteration in input sub factors and their relative importance weights which it expressed using method on this study can utilize for other locations. In addition, we found that if the SWOT analysis uses with AHP method base on Chang development analysis for determining the suitable areas of Bird watching, we are capable to reduce errors in AHP method and increase accuracy in selections areas. This manner is useful for strategic fuzzy assessment and presenting strategic solution. Therefore, comprehensive planning on suitable infrastructures should be implemented based on the suggested strategies in present study to prevent land use and land cover changes by wildlife tourism such as bird watching. By using the preferred frame in this study, decision makers can plan for each lake, dam and wetland and determine the best areas for tourist activities like bird watching. Conservation, protection and restoration of environment with its wildlife are guaranteed by using fuzzy assessment to provide reasonable strategies.

\section{References}

[1] Abedinzadeh, N., Abedinzadeh, F. and Abedi, T. (2013) Environmental Diagnosis by Eviave Methodology to Planning and Decision-Making for Municipal Waste Landfills in Iran. World Applied Sciences Journal, 21, 1640-1650.

[2] Anvary Rostamy, A., Khosroanjom, D., Niknafs, A., Rajabi, A. and Anvary Rostamy, A. 
(2014) IT Capability Impacts on Quality of Customer Service Process Using Fuzzy AHP. International Journal of E-Business Development, 4, 21-29.

[3] Gallego-Ayala, J. and Juízo, D. (2011) Strategic Implementation of Integrated Water Resources Management in Mozambique: An A'WOT Analysis. Physics and Chemistry of the Earth, Parts $A / B / C, 36,1103-1111$. http://dx.doi.org/10.1016/j.pce.2011.07.040

[4] Bas, E. (2013) The Integrated framework for Analysis of Electricity Supply Chain Using an Integrated SWOT-Fuzzy TOPSIS Methodology Combined with AHP: The Case of Turkey. International Journal of Electrical Power \& Energy Systems, 44, 897-907. http://dx.doi.org/10.1016/j.ijepes.2012.08.045

[5] Batuhan Ayhan, M. (2013) A Fuzzy AHP Approach for Supplier Selection Problem: A Case Study in a Gear Motor Company. International Journal of Managing Value and Supply Chains, 4, 11.

[6] Bottero, M., Comino, E. and Riggio, V. (2011) Application of the Analytic Hierarchy Process and the Analytic Network Process for the Assessment of Different Wastewater Treatment Systems. Environmental Modelling \& Software, 26, 1211-1224. http://dx.doi.org/10.1016/j.envsoft.2011.04.002

[7] Celik, M., Deha Er, I. and Fahri Ozok, A. (2009) Application of Fuzzy Extended AHP Methodology on Shipping Registry Selection: The Case of Turkish Maritime Industry. Expert Systems with Applications, 36, 190-198. http://dx.doi.org/10.1016/j.eswa.2007.09.004

[8] Chang, C., Wu, C., Lin, C. and Chen, H. (2007) An Application of AHP and Sensitivity Analysis for Selecting the Best Slicing Machine. Computers \& Industrial Engineering, 52, 296-307. http://dx.doi.org/10.1016/j.cie.2006.11.006

[9] Chang, D. (1992) Extent Analysis and Synthetic Decision, Optimization Techniques and Applications. Vol. 1, World Scientific, Singapore, 352.

[10] Connell, J. (2009) Birdwatching, Twitching and Tourism: Towards an Australian Perspective. Australian Geographer, 40, 203-217. http://dx.doi.org/10.1080/00049180902964942

[11] Delgado-Galvan, X., Izquierdo, J., Benítez, J. and Perez-García, R. (2014) Joint Stakeholder Decision-Making on the Management of the Silao-Romita Aquifer Using AHP. Environmental Modelling \& Software, 51, 310-322. http://dx.doi.org/10.1016/j.envsoft.2013.10.008

[12] Ebrahimzadeh, I. and Yari, M. (2013) Comparative Study of Functions Affecting the Behavioral Patterns of Tourists in Iran and America's Tourism Marketing Plan Utilizing SWOT Model. Journal of Service Science and Management, 6, 20-30.

[13] Evans, M. (1994) Important Bird Areas in the Middle East. Vol. 2, Birdlife International, Cambridge, UK.

[14] Fassó, A. and Perri, P. (2001) Sensitivity analysis. In: El-Shaarawi, A. and Piegorsch, W., Eds., Encyclopedia of Environmetrics, Vol. 4, Wiley, New York, 1968-1982.

[15] Ghanbarzadeh, H. and Behniafar, A. (2011) Evaluation of Strategic Factors of Ecotourism Development in Bazangan Lake with Emphasizing on the Environmental Values. Quarterly of Natural Geography, 4, 59-72. (In Persian)

[16] Gorener, A., Toker, K. and Ulucay, K. (2012) Application of Combined SWOT and AHP: A Case Study for a Manufacturing Firm. Procedia-Social and Behavioral Sciences, 58, 1525 1534. http://dx.doi.org/10.1016/j.sbspro.2012.09.1139

[17] Govindan, K., Kaliyan, M., Kannan, D. and Haq, A. (2014) Barriers Analysis for Green Supply Chain Management Implementation in Indian Industries Using Analytic Hierarchy Process. International Journal of Production Economics, 147, 555-568.

[18] Haji Vahabzadeh, A., Asiaei, A. and Zailani, S. (2015) Reprint of "Green Decision-Making 
Model in Reverse Logistics Using FUZZY-VIKOR Method. Resources, Conservation and Recycling, 104, 334-347. http://dx.doi.org/10.1016/j.resconrec.2015.10.028

[19] Hajinejad, A. and Yari, M. (2013) Ecotourism Strategic Planning "Using SWOT and TOPSIS Methods" Case: Forest Park of Boluran, Koohdasht. Geography and Development, 11, 177- 191.

[20] Hosseini Ezzabadi, J., Dehghani Saryazdi, M. and Mostafaeipour, A. (2015) Implementing Fuzzy Logic and AHP into EFQM Model for Performance Improvement: A Case Study. Applied Soft Computing, 36, 165-176. http://dx.doi.org/10.1016/j.asoc.2015.06.051

[21] Kabir, G. and Hasin, M.A.A. (2012) Multiple Criteria Inventory Classification Using Fuzzy Analytic Hierarchy Process. International Journal of Industrial Engineering Computations, 3, 123-132.

[22] Kajanus, M., Kangas, J. and Kurttila, M. (2004) The Use of Value Focused Thinking and A'WOT Hybrid Method in Tourism Management. Tourism Management, 25, 499-506. http://dx.doi.org/10.1016/S0261-5177(03)00120-1

[23] Kajanus, M., Leskinen, P., Kurttila, M. and Kangas, J. (2012) Making Use of MCDS Methods in SWOT Analysis-Lessons Learnt in Strategic Natural Resources Management. Forest Policy and Economics, 20, 1-9. http://dx.doi.org/10.1016/j.forpol.2012.03.005

[24] Kargar, B., Bahiraei, H. and Abasee Semnani, A. (2012) Spatial-Regional Planning in Iran Base on SWOT Index (Case Study: Iran-Turkmenistan Border Region). Journal of Environmental Planning, 5, 89-105.

[25] Kumar Mangla, S., Pradeep Kumar, P. and Kumar Barua, M. (2015) Risk Analysis in Green Supply Chain Using Fuzzy AHP Approach: A Case Study. Resources, Conservation and Recycling, 104, 375-390. http://dx.doi.org/10.1016/j.resconrec.2015.01.001

[26] Kurttila, M., Pesonen, M., Kangas, J. and Kajanus, M. (2000) Utilizing the Analytic Hierarchy Process (AHP) in SWOT Analysis-A Hybrid Method and Its Application to a Forest-Certification Case. Forest Policy and Economics, 1, 41-52. http://dx.doi.org/10.1016/S1389-9341(99)00004-0

[27] Lane, S. and Richards, K. (2001) The "Validation" of Hydrodynamic Models: Some Critical Perspectives. In: Anderson, M. and Bates, P., Eds., Model Validation: Perspectives in $\mathrm{Hy}$ drological Science, Wiley, Chichester, 413-438.

[28] Leskinen, L., Leskinen, P., Kurttila, M., Kangas, J. and Kajanus, M. (2006) Adapting Modern Strategic Decision Support Tools in the Participatory Strategy Process-A Case Study of a Forest Research Station. Forest Policy and Economics, 8, 267-278. http://dx.doi.org/10.1016/j.forpol.2004.06.007

[29] Liao, C. (2011) Fuzzy Analytical Hierarchy Process and Multi-Segment Goal Programming Applied to New Product Segmented under Price Strategy. Computers \& Industrial Engineering, 61, 831-841. http://dx.doi.org/10.1016/j.cie.2011.05.016

[30] Mahendran, P., Moorthy, M. and Saravanan, S. (2014) A Fuzzy AHP Approach for Selection of Measuring Instrument for Engineering College Selection. Applied Mathematical Sciences, 8, 2149-2161. http://dx.doi.org/10.12988/ams.2014.44232

[31] Makhdom, M. (2010) Foundation of Land Planning. Vol. 9, University of Tehran, Tehran, 289.

[32] Malczewski, J. (1999) Gis and Multi Criteria Decision Analysis. John Wiley \& Sons Inc., Hoboken.

[33] Moscardo, G. and Saltzer, R. (2004) Chapter 9. Understanding Wildlife Tourism Markets. In: Higginbottom, K., Ed., Wildlife Tourism: Impacts, Planning and Management, Common Ground Publishing on behalf of the Cooperative Research Centre for Sustainable 
Tourism, Victoria, Australia, 167-185.

[34] Neaupane, K. and Piantanakulchai, M. (2006) Analytic Network Process Model for Landslide Hazard Zonation. Engineering Geology, 85, 281-294.

http://dx.doi.org/10.1016/j.enggeo.2006.02.003

[35] Newsome, D., Dowling, R. and Moore, S. (2005) Wildlife Tourism. Channel View Publication (USA Library), North York, Ontario, Canada.

[36] Nezakati, R., Haeri Pour, S., Malmasi, S. and Lotfi, A. (2010) Guidelines on Wetland Habitats Zoning Base on MED WET System. Vol. 1, The Green Circle Press, 105.

[37] Omidi Tabrizi, N. (2010) Detecting on Landuse Change of BABOLSAR City Using Remote Sensing Data for Sustainable Planning in Environment. Master's Thesis, University of Tehran, Tehran, Fall, 105.

[38] Pasonen, M., Kurttila, M., Kangas, J., Kajanus, M. and Heinonen, P. (2000) Assessing the Priorities Using A'WOT among Resource Management Strategies at the Finish Forest and Park Service. Forest Science, 47, 534-541.

[39] Pesonen, M., Kangas, J., Kurttila, M. and Kajanus, M. (2001) Applying A'WOT to Choose a Management Strategy for the Forest Holding Owned by Private Partnership. In: Väyrynen, J. and Niskanen, A., Eds., International Symposium on Economic Sustainablity of SmallScale Forestry, IUFRO Working Unit 3.08.00: Small-Scale Forestry, 20-26 March 2001, Joensuu, Finland, Abstracts, 79.

[40] Pohekar, S. and Ramachandran, M. (2004) Application of Multi-Criteria Decision Making to Sustainable Energy Planning-A Review. Renewable and Sustainable Energy Reviews, 8, 365-381. http://dx.doi.org/10.1016/j.rser.2003.12.007

[41] Rabitz, H. (1989) System Analysis at the Molecular Scale. Science, 246, 221-226. http://dx.doi.org/10.1126/science.246.4927.221

[42] Reihanian, A., Binti Mahmood, N., Kahrom, E. and Hin, T. (2012) Sustainable Tourism Development Strategy by SWOT Analysis: Boujagh National Park, Iran. Tourism Management Perspectives, 4, 223-228.

[43] Rezaei, P., Rezaie, K., Nazari-Shirkouhi, S. and Jamalizadeh Tajabadi, M. (2013) Application of Fuzzy Multi-Criteria Decision Making Analysis for Evaluating and Selecting the Best Location for Construction of Underground Dam. Acta Polytechnica Hungarica, 10, 187205.

[44] Saaty, T. (1980) The Analytic Hierarchy Process: Planning, Priority Setting, Resource Allocation. McGraw-Hill, New York.

[45] Saaty, T. (1990) How to Make a Decision: The Analytic Hierarchy Process. European Journal of Operational Research, 48, 9-26. http://dx.doi.org/10.1016/0377-2217(90)90057-I

[46] Saltelli, A. (2000) What Is Sensitivity Analysis? In: Saltelli, A., Chan, K. and Scott, E., Eds., Sensitivity Analysis, Wiley, New York.

[47] Secer, S. and Ozgurler, M. (2012) Analysis of the Turkish Consumer Electronics Firm Using SWOT-AHP Method. Procedia-Social and Behavioral Sciences, 58, 1544-1554.

[48] Smardon, R. (2009) International Wetland Policy and Management Issues. In: Smardon, R., Ed., Sustaining the World $s$ Wetlands, Springer, New York, 1-20. http://dx.doi.org/10.1007/978-0-387-49429-6_1

[49] Talinli, I., Topuz, E., Aydin, E. and Kabakc1, S. (2011) A Holistic Approach for Wind Farm Site Selection by Using FAHP. In: Suvire, G.O., Ed., Wind Farm-Technical Regulations, Potential Estimation and Siting Assessment, InTech, 213-234.

[50] VanGriensven, A., Meixner, T., Grunwald, S., Bishop, T., Diluzio, M. and Srinivasan, R. 
(2006) A Global Sensitivity Analysis Tool for the Parameters of Multi-Variable Catchment Models. Journal of Hydrology, 324, 10-23.

[51] Waddell, P., Ulfarsson, G., Franklin, J. and Lobb, J. (2007) Incorporating Land Use in Metropolitan Transportation Planning. Transportation Research Part A: Policy and Practice, 41, 382-410. http://dx.doi.org/10.1016/j.tra.2006.09.008

[52] Yuksel, I. and Dagdeviren, M. (2007) Using the Analytical Network Process (ANP) in SWOT Analysis-A Case Study for a Textile Firm. Information Sciences, 177, 3364-3382. http://dx.doi.org/10.1016/j.ins.2007.01.001

[53] Zadeh, L. (1965) Fuzzy Sets. Information and Control, 8, 338-353. http://dx.doi.org/10.1016/S0019-9958(65)90241-X

[54] Zeng, J., Min, A. and Smith, N. (2007) Application of Fuzzy Based Decision Making Methodology to Construction Project Risk Assessment. International Journal of Project Management, 25, 589-600. http://dx.doi.org/10.1016/j.ijproman.2007.02.006

[55] Zhang, Q. (2012) Research on Tourist Attraction Performance Promoting Method Based on the SWOT Analysis Method. IERI Procedia, 1, 254-260.

http://dx.doi.org/10.1016/j.ieri.2012.06.040

[56] Zhu, K., Jing, Y. and Chang, D. (1999) A Discussion on Extent Analysis Method and Applications of Fuzzy AHP. European Journal of Operational Research, 116, 450-456. http://dx.doi.org/10.1016/S0377-2217(98)00331-2

Submit or recommend next manuscript to SCIRP and we will provide best service for you:

Accepting pre-submission inquiries through Email, Facebook, LinkedIn, Twitter, etc. A wide selection of journals (inclusive of 9 subjects, more than 200 journals)

Providing 24-hour high-quality service

User-friendly online submission system

Fair and swift peer-review system

Efficient typesetting and proofreading procedure

Display of the result of downloads and visits, as well as the number of cited articles

Maximum dissemination of your research work

Submit your manuscript at: http://papersubmission.scirp.org/

Or contact ojg@scirp.org 